\title{
An Exploratory Study to Assess the Awareness of Drivers and Conductors regarding First Aid Kit in Buses running in Sonipat.
}

\author{
Suman Lata ${ }^{1}$, Sangita Devi ${ }^{2}$ \\ ${ }^{1,2}$ (Assistant Professor, M.M. Institute of Nursing, Mullana, India)
}

\begin{abstract}
Road traffic accidents (RTA) are increasing in an alarming ways. Globally nearly 1.2 million people killed in RTA during the year 2002. Developing and under-developed countries accounted for $80 \%$ of these deaths. The first hand dealers of buses should be well aware of first line treatment so that the morbidity and mortality can be reduced. A non-experimental exploratory research approach was used for the present study. Sample for the present study were 60 drivers and conductors which were selected by selected by simple random sampling. Data collected was from structured interview questionnaire consist of multiple choice questions regarding awareness of first aid kit. Maximum numbers 14 of drivers had average knowledge and very less only 6 drivers had very good knowledge regarding first aid kit in buses running in Sonipat whereas maximum numbers of conductors had average knowledge and very less only 3 conductors had below average knowledge regrading first aid kit in buses running in Sonipat. There are number of Road Traffic accident increasing day by day so the first line of person who will deal with the first line of treatment are drivers and conductors who must be well aware of first aid kit. And the awareness training programme should be there for drivers and conductors so that their knowledge can be improved from average to good level.
\end{abstract}

Keywords: Awareness, Drivers, Conductors, First Aid Kit

\section{INTRODUCTION}

\section{Prevention by Knowing of Fast Track First Line of Treatment}

Spectacular advances made in health \& health related sciences have paid with dividends in bringing down the mortality and morbidity due to communicable diseases. This has resulted in longevity of life of the people. At the same time globalization has improved the socio economic status of the people resulting in changes in the life style of the people. The longevity of life and changes in the life styles has brought the entire spectrum of non-communicable disease and accidents to the forefront of health care delivery system. Road traffic accidents (RTA) are increasing in an alarming ways. Globally nearly 1.2 million people killed in RTA during the year 2002. Developing and underdeveloped countries accounted for $80 \%$ of these deaths. RTA accounts for $2.1 \%$ of total deaths and $21 \%$ of total injury. Projected estimations reveal that fatalities due to RTA will increase by $66 \%$ over the next 20 years and will be the 3rd leading cause of death by 2020 moving from its present 9 th position. ${ }^{1}$

In India every year RTA accounts for over 1,00,000 deaths, 2 million hospitalization, 7.7 million minor injuries and an estimated loss of Rs. 55,000 crores or nearly 3\% of the GDP every year. If the present scenario is continued, it is projected that deaths due to RTAs will be 1,50,000 and 2.8 million victims will be hospitalized by 2010. 1,85,000 deaths and 3.6million victims will be hospitalized by 2015.The social and psychological suffering of the injured persons is increased and their families and also families with RTA deaths are phenomenal. It is sad to note that, life saved due to advancements in health and health related sector is now being wasted on the roads. ${ }^{1}$

Pre hospital care in India is inconsistent and unreliable - with minimal, if any, medical intervention and long delays to hospital. There is a lack of state organized emergency ambulance services. The vast majority of ambulances are used for inter -hospital transfer -not for primary response. Finding a suitable vehicle at the accident site is not easy. Untrained members of the public usually shift the victims. However as a start, locally managed attempts to improve pre hospital care have begun within large population centres in India. ${ }^{2}$

In a study done at Kasturba Medical College, Manipal, Karnataka in 2001 on 331 victims of road traffic accident, revealed that the maximum number of victims $23(26 \%)$, were in the age group of 21-30 years, followed by $17(20 \%)$ in 41-50 years age group. Male to female ratio was 7:1. Among the 87 victims, 26(29.9\%) were pedestrians and $61 \%$ 
were occupants in various types of vehicles, of which 33(37.93\%) were two wheelers, $10(11.4 \%)$ were three wheeler occupants, 18 (20.68\%) were four wheelers occupants. Two wheelers are more prone for accidents as compared with three and four wheeler vehicles. ${ }^{3}$

A study conducted by department of Community Medicine, Kasturba Medical College, Mangalore, Karnataka , India on two wheeler accidents on Indian roads over the five years (2000-2004) with respect to age and sex of the victim, type of injury sustained, type of vehicle involved and time distribution of accidents. Data was retrospectively collected from the records at the Regional Transport Authority's office, office of superintendent of police and also from both the Traffic police stations of the Mangalore city. Test of significance was applied and $\mathrm{p}$ value $<0.05$ was taken to be significant. A total of 1,231 two wheeler accidents were recorded during 2000-2004. Majority (77\%) of the victims were in the age group 18-44 years. Accident rate among males (83\%) was higher than that among females (17\%). Five percent of the victims $(n=75)$ succumbed to injuries, of whom 45 died on the spot. Geared vehicles $(81 \%)$ were more commonly involved than those without gears. Highest numbers of accidents were seen during 6-10 pm. Study concluded that among the fatalities majority died at the spot. Hence first aid measures at the spot would be of great help. It is recommended to have a good support system and para medical training for the people managing the ambulance. Awareness should be created among general public. ${ }^{4}$

A study conducted by Department of Forensic Medicine UCMS, Shahdara, Delhi, on head injury victims in fatal road traffic accidents in Delhi revealed 31\% were the victims of Head injury in vehicular accidents. Although majority of the fatalities were on the spot quite a number of such victims survived for a varied period. A multipronged approach including the preventive and curative measures for this man-made calamity is the need of the hour. Amongst various preventive measures are wearing helmet be made compulsory for both the driver and pillion riders of two-wheelers, development of a safe traffic sense amongst the road users. Traffic Police should be honest, exemplary punishment for the reckless driver, decongestion of Delhi roads. The curative measures are facilities of CT scanners and neurosurgeons in all the major hospitals, provision of first-aid in the PCR (Police control room) vans, to institute immediate treatment to the victim without waiting for the medico-legal formalities, opening of more fully equipped Accident and trauma centres. It is high time the concerned authorities gave some serious thought towards this avoidable epidemic on Delhi roads. ${ }^{5}$

A study conducted on traumas in road accidents suggests that road accidents are now-a-days one of the most important cause of injuries, deaths and definitive invalidity, except the war casualties. All the developed countries are affected by these problems, and all the efforts are in progress to make aware the people, mostly the drivers, of all the possible preventive measures. The injuries affect in different ways the driver and the passenger, and the same safety devices designed to protect the travellers, as safety belts and air bags, can hit them with peculiar mechanisms. Very important are the correct steps of the first aid, the succession of the treatment maneuvers, and the environment were the patients can and must be treated. Every effort must be done to organize all the best the first, second and definite aid and treatment, together with the active and passive safety devices, and with a correct road education, to stop the true epidemic impact of the road accidents. ${ }^{6}$

Road traffic accidents (RTA) have become the leading cause of injury and death among the adult population in India. As the private hospitals have business motive, many private agencies have been emerged to provide first aid care to the victims through the ambulance services to serve the purpose of saving their lives. But the drivers are untrained and not skillful in managing the victims of RTA. Many a times, the victims expire on the way to the health care setting due to lack of immediate first aid measures which was really essential at times.

Hence, the investigator felt that there is a need to educate the ambulance drivers who have first contact with the victim, regarding immediate first aid measures.

There are chances to increase the number of accident as study conducted by Suman Lata showed $45 \%$ of the public were unable to identify any of the road signs while the above study revealed $55 \%$ of the students were unable to identify even one of the five given mandatory road signs. Conductor, driver and traffic police and authorities. This include more chances of accident as well as prepare the first line of treatment by first aid kit in buses and other vehicle $^{7}$ 


\section{MATERIAL \& METHOD}

A non-experimental exploratory research approach was used for the present study. Population of the study will be employees working as driver and conductor working among buses running in Sonipat. Sample for the present study was employees working as driver and conductors among buses running in Sonipat selected by simple random sampling and the sample size was 60 . Research variable for the present study was awareness of bus drivers and conductor regarding first aid kit. Tool for the present study was structured interview questionnaire consist of multiple choice questions regarding awareness of first aid kit. Content validity will be determined by the expert's opinion. Analysis for the present study was consist of descriptive statistics by using SPSS version 16.

\section{RESULTS}

A total of 60 (28 drivers and 33 conductors) were interviewed for present research work. Data was analysed with Microsoft excel software and SPSS version 17.

Table I Age Distribution of Drivers and Conductors According to their Age, N=60

\begin{tabular}{|c|c|}
\hline Age (In Years) & Number Of Staff \\
\hline$\leq 20$ & 1 \\
\hline $21-30$ & 21 \\
\hline $31-40$ & 19 \\
\hline $41-50$ & 15 \\
\hline$>50$ & 4 \\
\hline
\end{tabular}

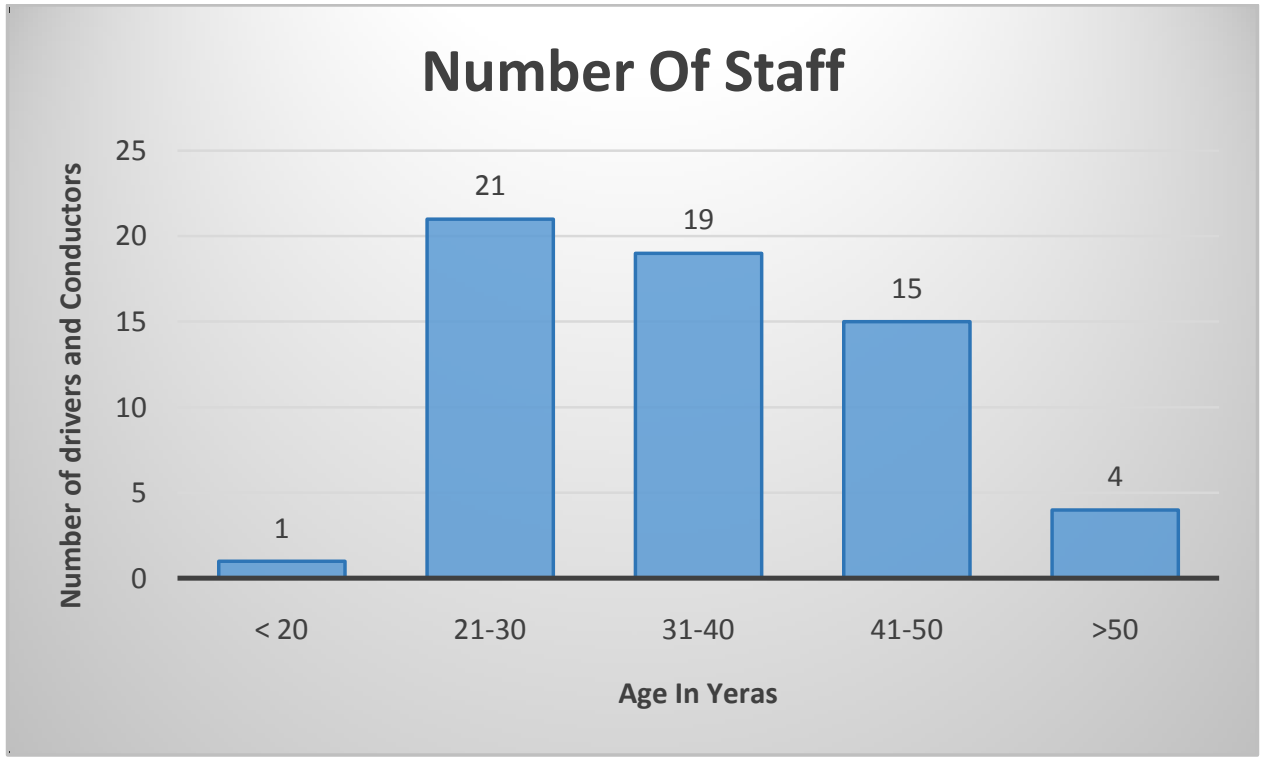

Fig.1: Age Distribution of Drivers And Conductors According To Their Age

Table I and Figure I shows that the maximum (21) numbers of Drivers and Conductors were from the age group of 
21-30 Years followed by (19 \& 15) the age group of 19 and 15 years and the least (4) number of drivers and conductors were from the age group of $>50$ years.

Table II Distribution of Work Experience of Drivers and Conductors According to their Age, N=60

\begin{tabular}{|l|l|}
\hline \multicolumn{1}{|c|}{ Work Experience( in Years) } & \multicolumn{1}{|c|}{ Number of Drivers and Conductors } \\
\hline$<1$ & 2 \\
\hline $1-5$ & 15 \\
\hline $6-10$ & 16 \\
\hline $10-15$ & 16 \\
\hline $16-20$ & 09 \\
\hline$>20$ & 2 \\
\hline
\end{tabular}

Table II reveals that the maximum numbers of drivers and conductors were having the work experience of 6-15 years and the least number of drivers and conductors were having the work experience of $<1$ years and $>20$ years.

Table III Distribution of Drivers and Conductors According To Their Educational Qualification N=60

\begin{tabular}{|c|c|}
\hline Educational Qualification & Number of Staff \\
\hline$<10$ & 8 \\
\hline $10^{\mathrm{TH}}$ & 16 \\
\hline $10+2$ & 19 \\
\hline GRADUATE & 15 \\
\hline POST-GRADUATE & 2 \\
\hline
\end{tabular}

Table III Reveal that the maximum (19)number of drivers and conductors were educated upto10+2 Standard followed(16 and 15) by 10 plus and Graduate standard and the least number of drivers and conductors were educated $<10^{\text {th }}$ standard.

Table IV Level of knowledge of drivers and conductors regarding first aid kit in buses running in Sonipat, N=60

\begin{tabular}{|c|c|c|c|c|}
\hline \multirow[t]{2}{*}{ Level of Knowledge } & \multicolumn{2}{|c|}{ Drivers } & \multicolumn{2}{|c|}{ Conductors } \\
\hline & $\mathbf{f}$ & $\%$ & $\mathbf{f}$ & $\%$ \\
\hline Very Good & 6 & 21 & 8 & 24 \\
\hline Good & 8 & 29 & 10 & 31 \\
\hline Average & 14 & 50 & 12 & 37 \\
\hline Below Average & 10 & 36 & 3 & 10 \\
\hline
\end{tabular}

Table IV shows that Maximum numbers 14 of drivers had average knowledge and very less only 6 drivers had very good knowledge regarding first aid kit in buses running in sonipat whereas maximum numbers of conductors had average knowledge and very less only 3 conductors had below average knowledge regrading first aid kit in buses running in Sonipat. 
Table V Awareness Regarding Availability, Requirement, Use, Got Training of first Aid Kit in buses runnin in Sonipat, $\mathrm{N}=60$

\begin{tabular}{|c|c|c|}
\hline \multirow{2}{*}{ Employees } & \multicolumn{2}{|c|}{ Awareness regrading Availability of First Aid Kit } \\
\cline { 2 - 3 } & Yes & 16 \\
\hline Drivers & 11 & 15 \\
\hline Conductors & 18 & 16 \\
\hline
\end{tabular}

\begin{tabular}{|c|c|c|}
\hline \multirow{2}{*}{ Employees } & \multicolumn{2}{|c|}{ Awareness regrading Requirement of First Aid Kit } \\
\cline { 2 - 3 } & Yes & 20 \\
\hline Drivers & 8 & 17 \\
\hline Conductors & 16 & 20 \\
\hline
\end{tabular}

\begin{tabular}{|c|c|c|}
\hline \multirow{2}{*}{ Employees } & Awareness regrading Use of First Aid Kit \\
\cline { 2 - 3 } & Yes & 16 \\
\hline Drivers & 12 & 16 \\
\hline Conductors & 17 & No \\
\hline
\end{tabular}

\begin{tabular}{|c|c|c|}
\hline \multirow{2}{*}{ Employees } & \multicolumn{2}{|c|}{ Awareness regarding Training of First Aid Kit } \\
\cline { 2 - 3 } & Yes & 18 \\
\hline Drivers & 10 & 17 \\
\hline Conductors & 16 & No \\
\hline
\end{tabular}

Table V reveals that maximum numbers of Conductors had awareness regarding Availability, Requirement, Use, Got Training of first Aid Kit in buses running in Sonipat whereas maximum numbers of drivers had no awareness regarding Availability, Requirement, Use, Got Training of first Aid Kit in buses running in Sonipat

\section{DISCUSSION}

Maximum (21) numbers of Drivers and Conductors were from the age group of 21-30 Years followed by (19 \& 15) the age group of 19 and 15 years and the least (4) number of drivers and conductors were from the age group of $>50$ years. Maximum numbers of drivers and conductors were having the work experience of 6-15 years and the least number of drivers and conductors were having the work experience of <1 years and > 20 years. Most (19) of drivers and conductors were educated upto10+2 Standard followed (16 and 15) by 10 plus and Graduate standard and the least number of drivers and conductors were educated $<10^{\text {th }}$ standard. Maximum numbers 14 of drivers had average knowledge and very less only 6 drivers had very good knowledge regarding first aid kit in buses running in sonipat whereas maximum numbers of conductors had average knowledge and very less only 3 conductors had below average knowledge regrading first aid kit in buses running in Sonipat. Maximum numbers of Conductors had awareness regarding Availability, Requirement, Use, Got Training of first Aid Kit in buses running in Sonipat whereas maximum numbers of drivers had no awareness regarding Availability, Requirement, Use, Got Training of first Aid Kit in buses running in Sonipat.

A similar study on Knowledge attitude and practices of undergraduate students regarding first aid measures was 
conducted at The Aga Khan University, Medical College, Karachi, Pakistan. It was carried out at six colleges of Karachi, three of which were medical colleges and three non-medical colleges. Knowledge was assessed regarding various emergency situations with the help of a questionnaire. A total of 446 students were interviewed. Seventy eight students (17.5\%) had formal First Aid (FA) training. The mean number of correct answers of students with FA training was $10.3(+/-3.5)$ as opposed to $8.58(+/-4.0)$ in those without FA training $(\mathrm{p}<0.001,95 \% \mathrm{CI})$ with a mean difference of $7.84 \%$. The mean number of correct answers by medical students with FA training was $11.2(+/-2.9)$ as opposed to $7.2(+/-3.43)$ by non-medical students $(\mathrm{p}<0.001,95 \% \mathrm{CI})$ with a mean difference of $18.14 \%$. Students having received formal first aid training scored better than those who had not $(\mathrm{p}<0.001)^{8}$ and a descriptive study on knowledge of the first aid kit contents among motor vehicles drivers was conducted at Slovenia. The data were gathered between March and April 2008 with the use of a questionnaire. The sample chosen for the study were 128 motor vehicle drivers ( 63 female and 65 male). The study revealed that all participants but one had the first aid kit in their vehicle. $29.7 \%$ of the respondents had the old first aid kit and $68.84 \%$ had the new one. Their knowledge of the first aid kit individual items was insufficient. The first aid bandage was best known article among the drivers. The used up material from the kit is rather quickly replaced with the new one by the majority of respondents, whereas only one third check the material expiry date of the first aid kit at least once a year. The study concluded with a low level of knowledge of the first aid kit contents has been confirmed. It is therefore necessary to focus more attention to motor vehicles driver's awareness about the first aid kit supplies, the purpose of particular items and their correct usage. It should be pointed out that nurses play an important role in providing and delivering proper information on the issue.

\section{REFERENCES}

[1] World Health Organization India Country Office collaborative Programme: Road Traffic Injury Prevention in India. India: Government of India; 2004-05

[2] Fitzgerald M, Dewan Y, O'Reilly G, Mathew J, McKenna C. India and the management of road crashes: Towards a national trauma system. Indian J Surg 2006; 68: 226-32

[3] Nayak P, Udit BD, Kumar N. An autopsy study of thoraco-abdominal trauma in road traffic accident cases. Journal of Karnataka Association of Medicolegal Sciences 2001; 10(1) : 18-22

[4] Jain A, Menezes RG, Kanchan T, Gagan S, Jain R. Two wheeler accidents on Indian roads--a study from Mangalore India. J Forensic Leg Med 2009 Apr; 16(3): 130-3

[5]Banerjee KK, Agarwal BB, Kohli A, Aggarwal NK. Study of head injury victims in fatal road traffic accidents in Delhi. Indian J Med Sci 1998 Sep; 52(9): 395-8.

[6] Picardi N. Traumas in road accidents. Ann Ital Chir 2005 Nov-Dec; 76(6): 505-515.

[7] Lata S., Singh R. Operationalization of Motor Vehicle Act, International Journal of Science and applies Research; 3(2):2016:40-46, 2016

[8] Khan A, Shaikh S, Shuaib F, Sattar A, Samani SA, Shabbir Q, Rasheed AZ. Knowledge attitude and practices of undergraduate students regarding first aid measures. J Pak Med Assoc 2010 Jan; 60(1): 68-72.

[9] Sterbenc I, Slabe D. Knowledge of the first aid kit contents among motor vehicles drivers. Obzornik Zdravstvene Nege 2009; 43 (1): 45-52. 